\title{
p38 $\alpha$ blockade inhibits colorectal cancer growth in vivo by inducing a switch from HIF1 $\alpha$ - to FoxO-dependent transcription
}

\author{
F Chiacchiera ${ }^{1}$, A Matrone ${ }^{1}$, E Ferrari ${ }^{1}$, G Ingravallo², G Lo Sasso ${ }^{3}$, S Murzilli ${ }^{3}$, M Petruzzelli ${ }^{3,4}$, L Salvatore ${ }^{3}$, A Moschetta ${ }^{3,4}$ \\ and C Simone ${ }^{\star, 1}$
}

Colorectal cancer cell (CRC) fate is governed by an intricate network of signaling pathways, some of which are the direct target of DNA mutations, whereas others are functionally deregulated. As a consequence, cells acquire the ability to grow under nutrients and oxygen shortage conditions. We earlier reported that $p 38 \alpha$ activity is necessary for proliferation and survival of CRCs in a cell type-specific manner and regardless of their phenotype and genotype. Here, we show that p38 $\alpha$ sustains the expression of HIF1 $\alpha$ target genes encoding for glycolytic rate-limiting enzymes, and that its inhibition causes a drastic decrease in ATP intracellular levels in CRCs. Prolonged inactivation of p38 $\alpha$ triggers AMPK-dependent nuclear localization of Fox03A and subsequent activation of its target genes, leading to autophagy, cell cycle arrest and cell death. In vivo, pharmacological blockade of $\mathrm{p} 38 \alpha$ inhibits CRC growth in xenografted nude mice and azoxymethane-treated Apc ${ }^{\mathrm{Min}}$ mice, achieving both a cytostatic and cytotoxic effect, associated with high nuclear expression of FoxO3A and increased expression of its target genes p21 and PTEN. Hence, inhibition of p38 $\alpha$ affects the aerobic glycolytic metabolism specific of cancer cells and might be taken advantage of as a therapeutic strategy targeted against CRCs.

Cell Death and Differentiation (2009) 16, 1203-1214; doi:10.1038/cdd.2009.36; published online 3 April 2009

Colorectal cancer is the second leading cause of death for tumors in the western world because of a high percentage of metastatic disease, which shows a 5-year survival rate of approximately $10 \%{ }^{1}$

Recently, the genomic landscape of colorectal cancer has been unveiled, ${ }^{2}$ enriching the list of genes mutations of which may be causative of human tumors and revealing that other pathways, such as the $\mathrm{Pl}_{3} \mathrm{~K} / \mathrm{PTEN} / \mathrm{Akt}$ and the JNK cascades, are deregulated in colorectal cancer cells (CRCs), besides the well-known Wnt, p53, K-ras, LKB1/AMPK and TGF $\beta .^{3,4}$ Intriguingly, these pathways not only regulate the proliferation and the survival of CRCs, but also affect their cancer-specific metabolism. Indeed, increased glycolysis, even in the presence of high oxygen tension, is a common feature of tumor cells (the so-called 'Warburg effect'), which produce $50 \%$ of their ATP through the glycolytic flux, versus the $10 \%$ observed in normal cells. ${ }^{5}$ It is worth noting that cancer cells retain their metabolic phenotypes in culture under normoxia, which implies that cancer-specific aerobic glycolysis is constitutively activated through stable genetic or epigenetic mutations. ${ }^{6}$ A key mechanism sustaining aerobic glycolysis is the stabilization and activation of the transcription factor $\mathrm{HIF} 1 \alpha$, which regulates the expression of the glucose transporter GLUT1, of the rate-limiting enzymes HK1/2 and
PKM2, and of LDHA, the enzyme responsible for the conversion of pyruvate into lactate. ${ }^{7}$ HIF1 $\alpha$ strongly links aerobic glycolysis to carcinogenesis, representing one of the crossroads for tumor suppressor and oncogenic pathways. ${ }^{7,8}$

The emerging picture suggests that several pathways involving multiple cross talks regulate tightly linked cellular processes. A paradigm of this view is represented by the p38 pathway, which is involved in proliferation, differentiation, metabolism and cell death. ${ }^{9-11}$ This cascade regulates the activity of several transcription factors in a signal-dependent and tissue-specific manner ${ }^{12}$ and cross talks with the JNK, LKB1/AMPK and $\mathrm{PI}_{3} \mathrm{~K} /$ Akt pathways. ${ }^{13-15}$ In mammals, four genes encode for different p38 isoforms, $\mathrm{p} 38 \alpha, \beta, \gamma$ and $\delta$. p38 $\alpha$ knockout mice die at embryonic stages because insufficient vascularization of the placenta, whereas specific deletion in the whole embryo, but not in the placenta, causes death several days after birth, probably because of lung dysfunction. ${ }^{16}$ It is interesting to note that histological analysis of these mice did not reveal alterations in other organs, including the intestine. In CRCs, genetic inactivation of ASK-1, one of the upstream activators of the p38 kinases, exerts anti-tumor effects both in vitro and in vivo by inhibiting the serum-induced phosphorylation of p38, thus causing growth arrest and cell death. ${ }^{17}$ Furthermore, the activation of

\footnotetext{
${ }^{1}$ Laboratory of Signal-dependent Transcription, Department of Translational Pharmacology (DTP), Consorzio Mario Negri Sud, Santa Maria Imbaro (Ch), 66030, Italy; ${ }^{2}$ Department of Pathological Anatomy, University of Bari, Bari, 70124, Italy; ${ }^{3}$ Laboratory of Lipid Metabolism and Cancer, Department of Translational Pharmacology (DTP), Consorzio Mario Negri Sud, Santa Maria Imbaro (Ch), 66030, Italy and "Clinica Medica Murri', Department of Internal and Public Medicine, University of Bari, Bari, 70124, Italy

*Corresponding author: C Simone, Department of Translational Pharmacology, Consorzio Mario Negri Sud, Via Nazionale 8A, Santa Maria Imabro, Ch 66030, Italy. Tel: + 39087257 0344; Fax: + 39087257 0299; E-mail: simone@ negrisud.it Keywords: p38 $\alpha$; autophagy; FoxO; HIF1 $\alpha$; colorectal cancer cell metabolism Abbreviations: CRC, Colorectal cancer cell; AOM, azoxymethane; i.p., intraperitoneal; ChIP, Chromatin immunoprecipitation Received 03.12.08; revised 27.2.09; accepted 27.2.09; Edited by RA Knight; published online 03.4.09
} 
p38 confers transendothelial migration and survival advantages to HT29 CRCs. ${ }^{18}$

We recently reported that $\mathrm{p} 38 \alpha$ is required for CRC proliferation and survival, as genetic depletion (by RNAi) or pharmacological blockade (by SB202190) of its kinase activity induce autophagy, growth arrest and cell death in a cell typespecific manner in vitro. ${ }^{19}$ In eukaryotic cells, autophagy represents a survival response to metabolic stress; however, under persistent stress conditions it can also result in cell death. Basically, the autophagic flux consists of sequential steps, controlled by the ATG proteins, leading to degradation of cytoplasmic material and recovery of amino acids and fatty acids that sustain cell metabolism. ${ }^{20}$ It is noted that inhibition of SB202190-dependent autophagy in CRCs not only fails to increase viability, but even fosters cell death by inducing apoptosis. ${ }^{19}$ These results indicate that the autophagic response to $\mathrm{p} 38 \alpha$ blockade initially represents a survival reaction, whereas persistent inactivation of the kinase leads to cell death. Indeed, re-activation of $p 38 \alpha$ induces a timedependent reduction of autophagic vacuolation with a slow re-entry into the cell cycle. ${ }^{19,21}$

In this study, we aimed to verify whether the effect of p38 $\alpha$ blockade on CRC pathophysiology is dependent on deregulation of metabolic cascades. In particular, inhibition of p38 $\alpha$ may entail modifications in cancer-specific aerobic glycolysis, which is highly activated in CRCs. ${ }^{22}$ To this purpose, we first started to elucidate the molecular scenario imposed by $p 38 \alpha$ blockade in vitro, then we evaluated the effect of SB202190 on tumor growth in xenografted nude mice and azoxymethane (AOM)-treated $\mathrm{Apc}^{\mathrm{Min}}$ mice. Our findings indicate that $p 38 \alpha$ blockade inhibits colorectal cancerogenesis by inducing a transcriptional switch from $\mathrm{HIF} 1 \alpha$ - to FoxOdependent gene expression.

\section{Results}

p38 $\alpha$ blockade induces FoxO nuclear accumulation, its binding to promoters and the expression of target genes. Our earlier study showed that p38 $\alpha$ inhibition in CRCs induces autophagy, cell cycle arrest and cell death accompanied by the upregulation of $G A B A R A P$, a member of the ATG family genes, and the downregulation of cyclins $A$ and $E{ }^{19}$ Here, we extend our analysis to relevant genes involved in autophagy, proliferation and survival (Supplementary Figures 1 and 3). As HT29 and LS174T CRCs displayed similar cellular responses to SB202190 treatment, we made use of the 'CONFAC' software ${ }^{23}$ to score the 3000-bp regions upstream of the transcription start site of genes that were upregulated in both cell lines in the search for transcription factor-binding sequences. The in silico analysis revealed that the promoters of the SB202190 treatment-responsive genes were significantly enriched in the conserved consensus core recognition motif FHRE specific for FoxO proteins, an evolutionarily conserved family of transcription factors involved in proliferation/ arrest, survival/death, metabolism and autophagy. ${ }^{24}$ Our subsequent analysis revealed an interesting pattern of upregulated expression for several known FoxO target genes on p38 $\alpha$ blockade (Supplementary Figures 2 and 3).
Some of them code for proteins playing a role in cell cycle arrest and cell death (cyclin G2, Rbl2/p130, Gadd45, Bcl-6 and Bim), whereas others code for proteins involved in cell metabolism (PGC1 $\alpha$, PEPCK and UCP2). Besides, some of the genes that were found to be downregulated (Supplementary Figures 1 and 3), like the cyclin genes, are reported to be negatively regulated by FoxO. ${ }^{25}$

The FoxO family of transcription factors is composed of FoxO1, FoxO3A, FoxO4 and FoxO6, which are emerging as tumor suppressor proteins. ${ }^{26}$ FoxO transcription factors are mainly regulated by nuclear/cytoplasmic shuttling dictated by signal-dependent phosphorylation of target residues. As FoxO3A has been shown to bind to the promoters of MAP1LC3, GABARAPL1, ATG12, BNIP3 and BNIP3L, ${ }^{27,28}$ we investigated its role in the SB202190-dependent gene expression reprograming observed in CRCs. Consistently, on pharmacological blockade of p38 $\alpha$ or its genetic ablation by specific RNAi, FoxO3A accumulates into the nuclei of HT29 and LS174T cells, as showed by immunofluorescent staining (Figure $1 \mathrm{a}-\mathrm{c}$ ) and immunoblot analysis of cytoplasmic and nuclear fractions (Figure 1d). Furthermore, FoxO3A specifically binds to the regulatory regions of all the target genes tested by Chromatin Immunoprecipitation (ChIP) (Figure 1e) and co-localizes with phospho-activated Polymerase II at these sites (Figure 1g). Re-activation of $\mathrm{p} 38 \alpha, 48 \mathrm{~h}$ after SB202190 removal, was associated with significant dissociation of FoxO3A from the DNA of target genes (Figure 1e), in agreement with the time-dependent reduction in autophagic vacuolation and the slow re-entry into the cell cycle (Figure if and $h$ ). These results suggest that FoxO3A is one of the transcriptional mediators of SB202190-dependent effects in CRCs. Indeed, genetic ablation of FoxO3A by specific RNAi significantly inhibited the SB202190-dependent autophagic flux in HT29 cells, preventing accumulation of Gabarapl1 which is encoded by the ATG gene showing the highest transcriptional induction on $\mathrm{p} 38 \alpha$ blockade (Supplementary Figure 1) - and the subsequent formation of cytoplasmic dots and autophagolysosomes (Figure 2).

p38 $\alpha$ blockade promotes the activation of signaling pathways that favor FoxO nuclear localization and transcriptional activity. FoxO proteins are regulated by phosphorylation-dependent nuclear/cytoplasmic shuttling as a result of the activity of the Akt and JNK kinases, which is evolutionarily conserved from invertebrates to humans. Akt directly phosphorylates FoxO3A at the T32, S253 and S315 residues and targets it to bind to the 14-3-3 nuclear export protein, thus allowing its cytoplasmic accumulation and subsequent degradation. On the other hand, JNK1 phosphorylates the 14-3-3 protein inhibiting its binding to FoxO3A and promoting FoxO3A nuclear localization even in the presence of activated $\mathrm{Akt}^{24}$ Immunoblot analysis of SB202190-treated CRCs revealed the time-dependent reduction of S473 Akt phospho-activation together with the enrichment of the PTEN phosphatase (Figure 3a), a pattern that correlates with the decreased Akt-dependent phosphoinhibition of FoxO3A on the T32 and $\mathrm{S} 253$ residues (Figure $3 a$ and data not shown). Conversely, JNK was significantly phospho-activated in both cell lines (Figure 3b). 
a

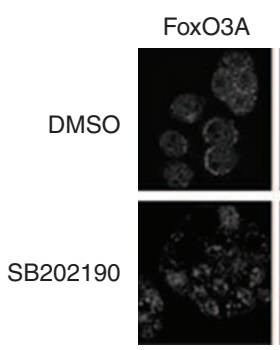

HT29

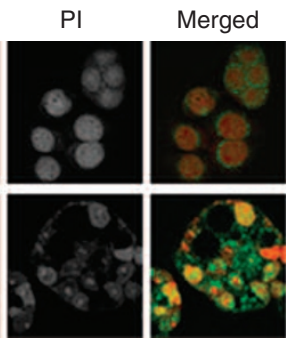

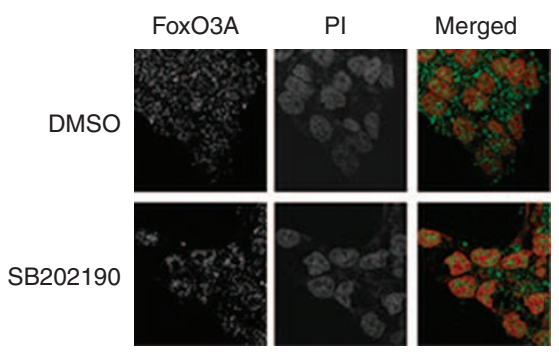

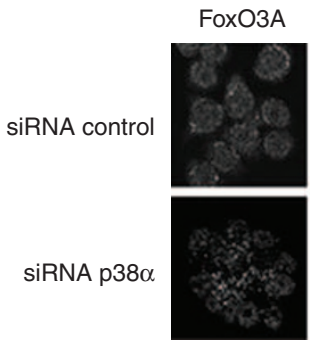

HT29

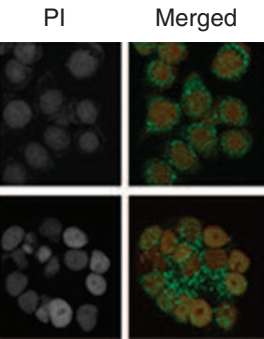

d

$$
{ }^{\text {CYTOPLASM }}{ }^{\text {HT29 }} \frac{\text { NUCLEUS }}{\text { DMSO SB202190 DMSO SB202190 }}
$$

FoxO3A

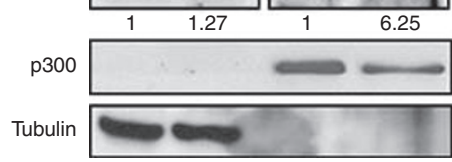

e

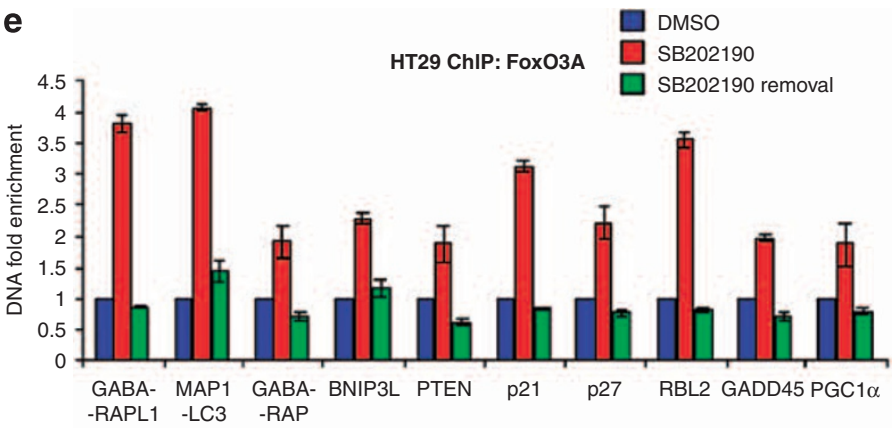

g

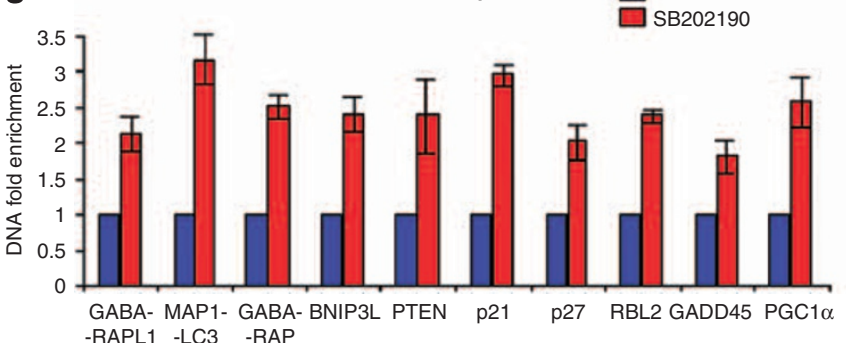

f

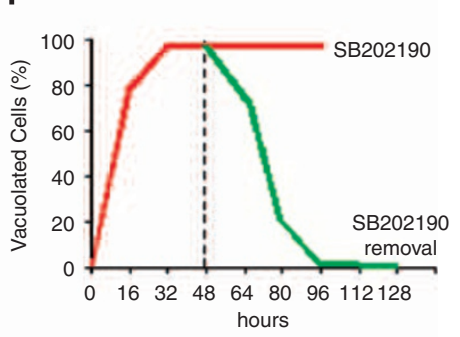




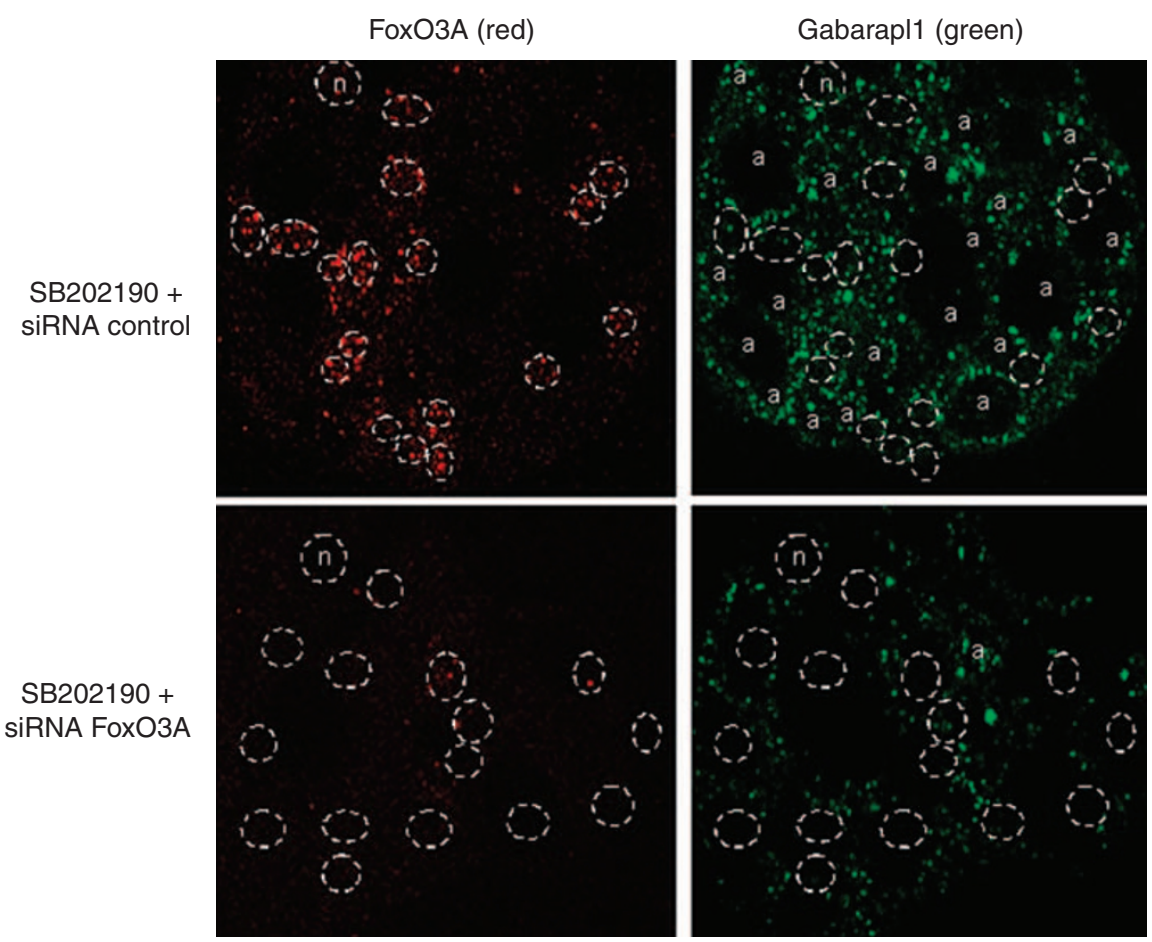

Figure 2 Genetic ablation of FoxO3A significantly inhibits the SB202190-dependent autophagic flux in HT29 cells. Confocal analysis of HT29 cells transfected with $100 \mathrm{nM}$ FoxO3A-specific or control siRNAs and then cultured in the presence of SB202190 for $24 \mathrm{~h}$. Nuclei (n) are evidenced by dotted circles and autophagolysosomes (a) are indicated

a

HT29

LS174T

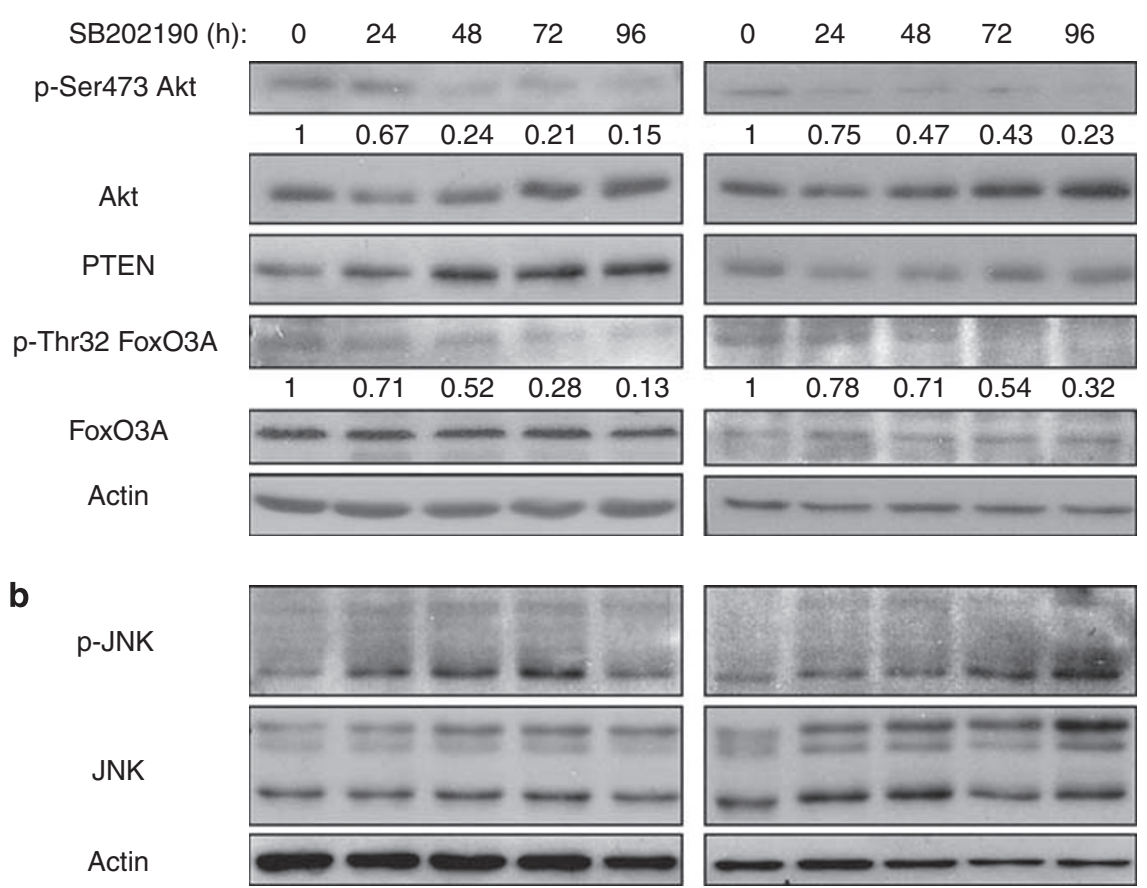

Figure 3 SB202190 switches signaling pathways activation promoting FoxO nuclear localization. (a and b) Immunoblots analysis showing protein expression and covalent modifications in HT29 and LS174T cells cultured in the absence or presence of SB202190 for the indicated periods of time. The values indicated are the results of the densitometric analysis of the phosphorylated forms of the indicated proteins normalized against their total forms and the loading controls (arbitrary units, $\mathrm{SB} 202190 \mathrm{Oh}=1$ ) 
detecting a time-dependent increase of the activated form of the kinase (Figure 4a). Employment of Compound $\mathrm{C}$, an AMPK-specific inhibitor, abolished the phenotype acquired by CRCs on SB202190 treatment and drastically reduced the induction of FoxO target genes (Figure $4 \mathrm{~b}$ and $\mathrm{c}$ ), indicating that AMPK is required for the cellular response of CRCs to p38 $\alpha$ blockade. Further characterization of these cells revealed that AMPK inhibition prevents nuclear accumulation
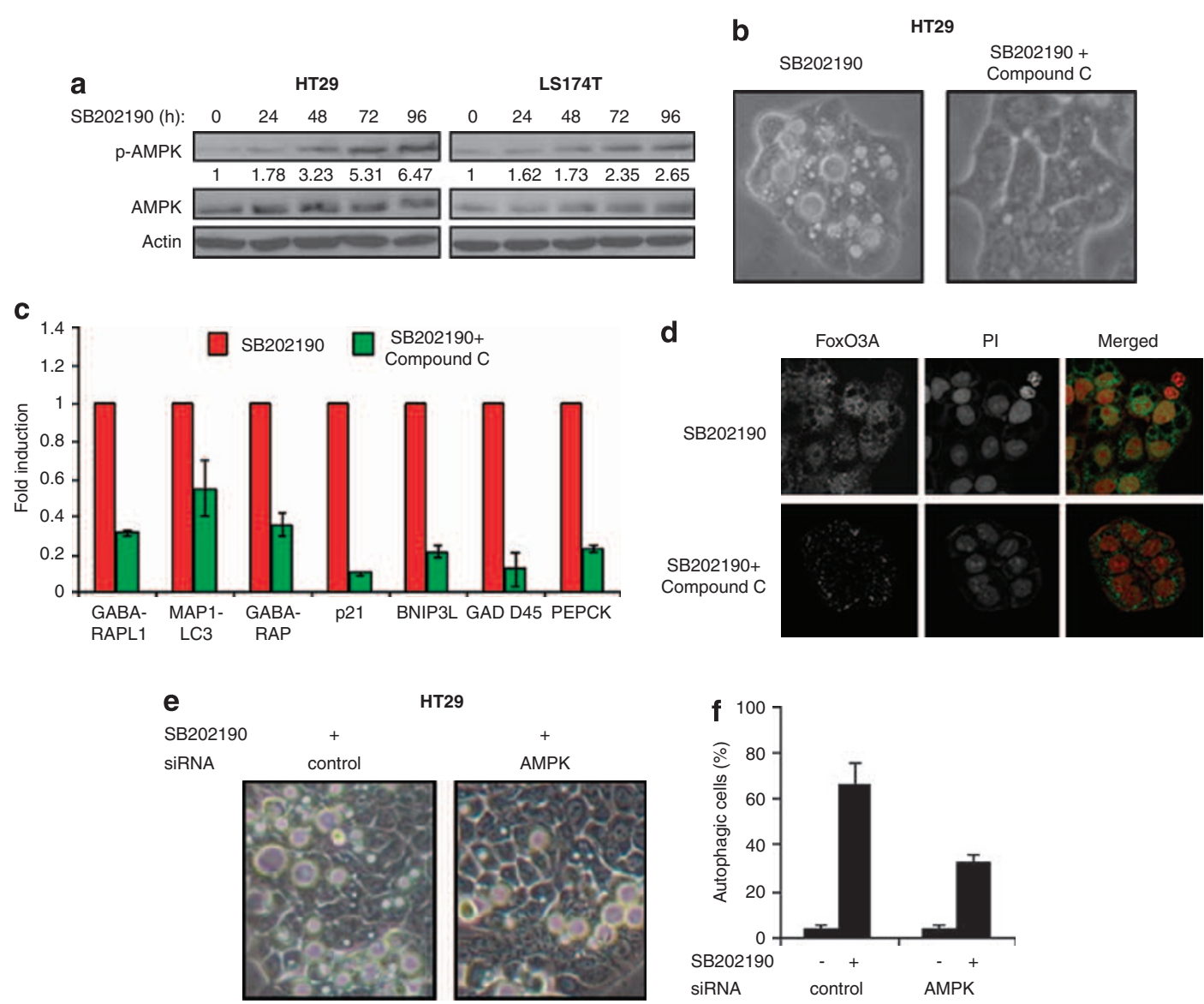

HT29
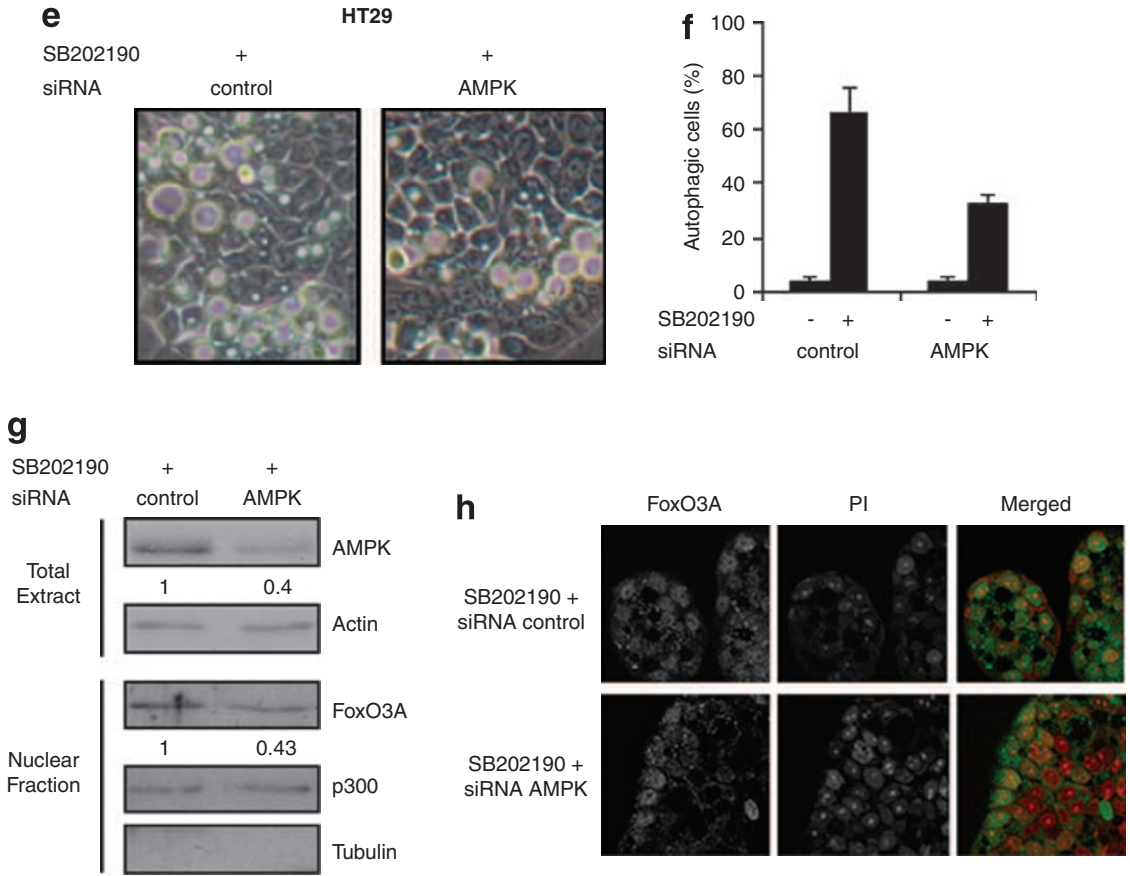

Figure 4 AMPK activation is required for FoxO3A-dependent cellular response to $\mathrm{p} 38 \alpha$ blockade in CRCs. (a) Immunoblot analysis of AMPK phospho-activation in SB202190-treated CRCs. The values indicated are the results of the densitometric analysis of phosphorylated AMPK normalized against total AMPK and the loading controls (arbitrary units, SB202190 Oh=1). (b-d). HT29 cells were cultured in the presence of SB202190 or a combination of SB202190 and Compound C for $24 \mathrm{~h}$. The extent of autophagic vacuolation was estimated by phase contrast microscopy (b). Quantitative real-time PCR analysis revealing the expression of FoxO target genes involved in autophagy, cell cycle arrest, cell death and metabolism (c). Confocal analysis showing the nuclear localization of FoxO3A. Nuclei were stained with propidium iodide (PI) (d). (e-h) HT29 cells were transfected with $100 \mathrm{nM}$ AMPK-specific or control siRNAs and then cultured in the presence of SB202190 for $24 \mathrm{~h}$. Phase contrast microscopy analysis (e). The extent of autophagy induction was quantified by scoring the percentage of autophagic cells (f). Immunoblots showing the expression of AMPK in total extracts and of FoxO3A in nuclear extracts. Tubulin and $\mathrm{p300}$ were used as fractionation controls. The values indicated are the results of the densitometric analysis of AMPK and FoxO3A protein levels normalized against loading controls (arbitrary units, SB202190/siRNA control $=1)(\mathbf{g})$. Confocal analysis showing the nuclear localization of FoxO3A. Nuclei were stained with propidium iodide $(\mathrm{PI})(\mathrm{h})$ 
of FoxO3A in SB202190-treated HT29 CRCs (Figure 4d). These pharmacological evidences were further confirmed by the observation that transient genetic ablation of AMPK significantly counters the effects of SB202190 treatment by inhibiting nuclear localization of FoxO3A, as shown by transfection of HT29 cells with siRNAs targeted against AMPK (Figure 4e-h).

p38 $\alpha$ sustains HIF1 $\alpha$ protein expression and transcription of HIF1 $\alpha$ target genes. Our hypothesis that p38 $\alpha$ might be involved in the regulation of essential metabolic cascades in CRCs was supported by the fact that CRCs responded to the inhibition of $\mathrm{p} 38 \alpha$ by inducing autophagy and phospho-activation of AMPK, a kinase activated by decreased ATP/AMP ratio, together with the
AMPK-dependent upregulation of FoxO target genes involved in cellular energy production. To test this hypothesis, we evaluated the ATP intracellular levels in SB202190-treated CRCs compared with DMSO control cells. Within the first hours of treatment, p38 $\alpha$ blockade caused a rapid decrease in ATP levels, which was then recovered at longer time points (Figure 5a). The time-dependent reactivation of ATP synthesis correlated to the kinetics of the autophagic vacuolation described, ${ }^{20}$ suggesting that induction of the autophagic flux might be one of the mechanisms responsible for buffering the acute energy need in CRCs.

Cancer cells predominantly produce ATP by constitutively activated aerobic glycolysis because of the stabilization and activation of the transcription factor $\operatorname{HIF} 1 \alpha$, which regulates

\section{a}

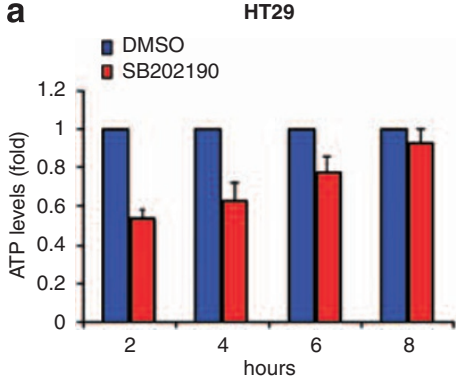

C

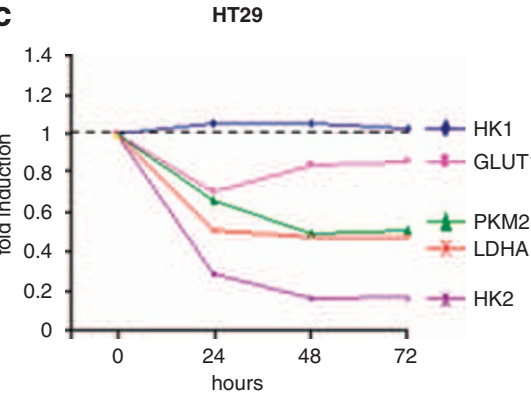

e

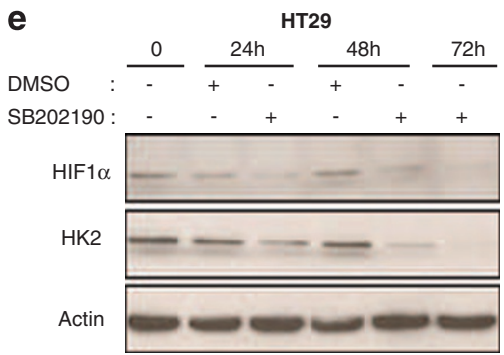

b
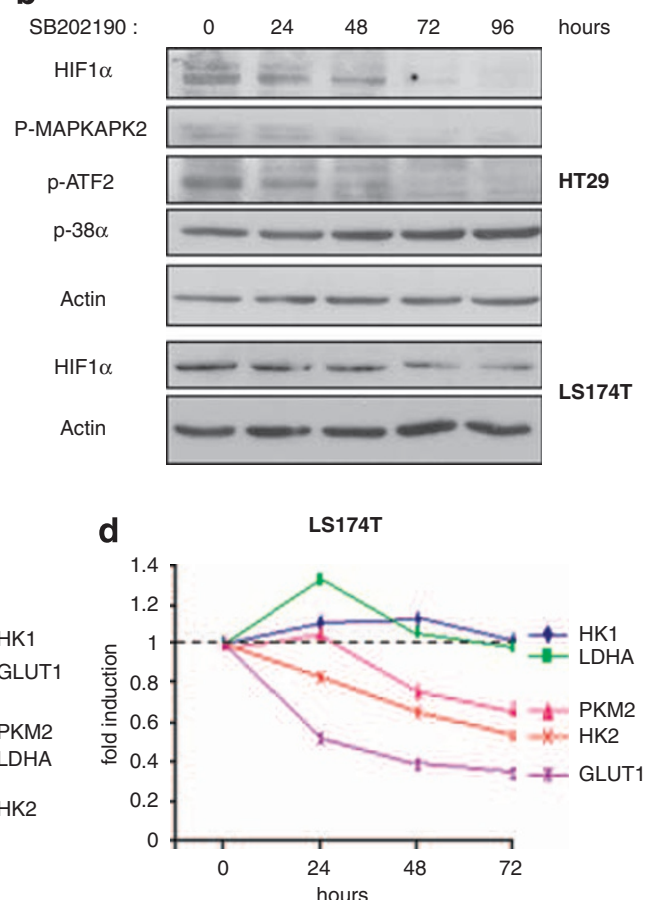

f

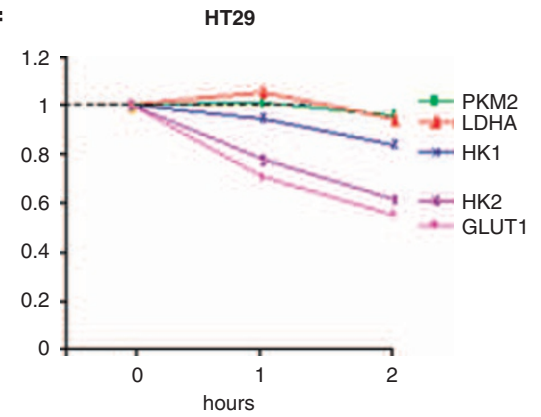

Figure 5 p38 $\alpha$ sustains HIF1 $\alpha$ protein expression and transcription of HIF1 $\alpha$ target genes. (a) ATP levels were measured in HT29 cells treated or not with SB202190 for up to $8 \mathrm{~h}$. (b) HIF1 $\alpha$ protein levels were evaluated by immunoblot in CRCs cultured in the presence of SB202190 for the indicated periods of time. Samples were probed for phospho-MAPKAPK2 and -ATF-2, two well-established p38 substrates, as a control of p38 $\alpha$ inhibition. (c, $\mathbf{d}$ and $\mathbf{f}$ ) Quantitative real-time PCR analysis of HIF1 $\alpha$ target genes involved in aerobic glycolysis. HT29 and LS174T cells were cultured in the absence or presence of SB202190 for the indicated period of times. The quantitative normalization of the cDNAs was carried out using GAPDH and $\beta$-actin amplifications as internal control. Values are expressed as fold induction with respect to untreated control cells. (e) HIF1 $\alpha$ and HK2 protein levels were analyzed by immunoblot in HT29 cells cultured in either the absence (DMSO) or the presence of SB202190 for up to $72 \mathrm{~h}$ 
the expression of genes encoding for glucose transporters and rate-limiting enzymes. ${ }^{9}$ Earlier reports indicate that $\mathrm{p} 38 \alpha$ is responsible for the stabilization of HIF1 $\alpha$ in hypoxic MEFs and in pancreatic cancer cells. ${ }^{30,31}$ To ascertain whether $\mathrm{HIF} 1 \alpha$ expression is regulated by $\mathrm{p} 38 \alpha$ in $\mathrm{CRC}$, we measured its protein levels in untreated cells and during SB202190dependent inhibition of $\mathrm{p} 38 \alpha$. We found that CRCs display significant levels of HIF $1 \alpha$ under normoxia, which decrease in a time-dependent manner along SB202190 treatment (Figure $5 \mathrm{~b}$ and $\mathrm{e})$. The expression profile of $\mathrm{HIF} 1 \alpha$ targets showed that a specific subset of genes, including those coding for GLUT1, $\mathrm{HK} 2, \mathrm{PKM} 2$ and LDHA, is significantly downregulated by $\mathrm{p} 38 \alpha$ blockade in CRCs (Figure 5c and d). Consistently, HK2 protein levels parallel those of HIF1 $\alpha$ protein in SB202190treated HT29 cells (Figure $5 \mathrm{e}$ ). These data indicate that $\mathrm{p} 38 \alpha$ is necessary to sustain HIF $1 \alpha$-dependent aerobic glycolysis in CRCs. To elucidate whether transcriptional regulation of these genes is responsible for the rapid decrease of ATP levels, we measured their expression at shorter time points. Intriguingly, the decrease of the mRNA levels of GLUT1 and HK2 was detectable within the first hours of SB202190 treatment, a pattern compatible with the urgent energy need observed in CRCs (Figure 5f).

SB202190 inhibits colorectal cancer growth in vivo. To investigate the impact of $p 38 \alpha$ blockade on colorectal cancer formation in vivo, we injected LS174T cells into each flank of athymic nude mice. Once the tumors reached a measurable volume, we continuously inhibited $\mathrm{p} 38 \alpha$ by daily intraperitoneal (i.p.) injection of SB202190. We used three different concentrations of SB202190 - 0.01, 0.05 and $0.1 \mu \mathrm{mol} / \mathrm{kg}$ body weight, or the corresponding DMSO amount as a vehicle control - to perform a dose-curve evaluation. We found that SB202190 treatment inhibits tumor growth in nude mice in a dose-dependent manner, with $0.05 \mu \mathrm{mol} / \mathrm{kg}$ body weight being the concentration with the best dose/effect ratio, capable of inducing a $50 \%$ reduction in tumor volume (Figure 6a). This concentration was then used in mice injected with HT29 cells. Significantly, HT29-derived tumors showed a $62 \%$ decrease in volume (Figure $6 \mathrm{~b}$ ).

The histopathological analysis of LS174T- and HT29derived colorectal tumor specimens revealed central areas of necrosis with neutrophilic and lymphoid infiltrates that were significantly detectable in all tumors treated with SB202190 $0.05 \mu \mathrm{mol} / \mathrm{kg}$ body weight (Figure $6 \mathrm{c}$ and d). Necroinflammatory areas were sometimes delimited by fibroblastic and vessel proliferation representing reparative tissue replacing neoplastic cells. No considerable neoplastic regression was present in untreated CRC-derived tumors, and apoptotic nuclear debris were comparable between treated and untreated cancer tissues. It is interesting to note that more than $80 \%$ of untreated tumor cells displayed nuclear anti-Ki67 positivity, a marker of the proliferation index, whereas this percentage significantly declined below $50 \%$ in tumors treated with SB202190 $0.05 \mu \mathrm{mol} / \mathrm{kg}$ body weight (Figure $6 \mathrm{c}$ and d). Moreover, p38 $\alpha$ blockade induced FoxO3A nuclear accumulation in cancer cells, revealing the activation of the transcription factor in SB202190-treated CRCs both cultured in vitro and injected in nude mice (Figure 6e). The analysis of LS174T-derived tumors treated with SB202190 $0.01 \mu \mathrm{mol} / \mathrm{kg}$ body weight revealed that lower doses of SB202190 were also able to produce an increase in areas of central necrosis, although to a lesser extent (Supplementary Figure 4). Fascinatingly, $40 \%$ of tumors treated with $0.1 \mu \mathrm{mol} / \mathrm{kg}$ body weight displayed only few sporadic foci of cancer cells straggled in between inflammatory cells and tissue debris (Supplementary Figure 4).

These findings show that SB202190 exerts both a cytostatic and cytotoxic effect in vivo, reminiscent of the induction of growth arrest and cell death described in vitro, and encouraged us to test this inhibitor in a mouse colorectal cancer model. To this purpose, we made use of $\mathrm{Apc}^{\mathrm{Min}}$ mice treated with $\mathrm{AOM}$, a colon-selective carcinogen. ${ }^{32,33}$ These mice carry a heterozygous mutation of the APC gene and resemble human familial adenomatous polyposis patients because of their inherited predisposition to form multiple tumors in the intestinal tract. However, they differ from humans in terms of cancer distribution and histology, thus making the use of AOM necessary to induce a robust tumor response in the large bowel. ${ }^{34}$ Thus, 4-month-old Apc ${ }^{\mathrm{Min}}$ mice were first administered with AOM once a week for 4 weeks, then, 1 month later, they were subjected to daily i.p. injections of SB202190 $0.05 \mu \mathrm{mol} / \mathrm{kg}$ body weight or DMSO. At day 14 of treatment, macroscopic examination of the bowel clearly showed a significant reduction in tumor size in both the small intestine and the colon of SB202190-treated $\mathrm{Apc}^{\mathrm{Min}}$ mice compared with controls (Figure $7 \mathrm{a}$ and $\mathrm{b}$ ). Overall, the analysis of hematoxylin and eosin stained sections revealed the presence of several adenomatous polyps variably pedunculated in DMSO-treated Apc ${ }^{\mathrm{Min}}$ mice (Figure $7 \mathrm{c}$ and d). Most of the adenomatous glands were irregular and displayed stratified pencil-shaped nuclei of various size, with glandular cells showing mucus depletion. Sometimes, carcinomatous transformation was detected (Figure 7d). The stalk consisted of normal mucosa, including muscolaris mucosae, submucosal tissue and a characteristic microvasculature with elongated and dilated vessels. In contrast, the intestinal polyps detected in SB202190-treated Apc ${ }^{\mathrm{Min}}$ mice were not pedunculated and displayed scattered adenomatous glands. Moreover, elevated expression of the cell proliferation marker PCNA was restricted to few glands, emphasizing a limited adenomatous component compared with DMSO-treated $\mathrm{Apc}^{\mathrm{Min}}$ mice (Figure 7e). Also, the lamina propria observed in SB202190treated $\mathrm{Apc}^{\mathrm{Min}}$ mice contained focally abundant inflammatory cells, probably replacing adenomatous glands (Figure $7 d$ ). Malignant transformation was never identified. In agreement with the molecular features detected on p38 $\alpha$ inhibition in $\mathrm{CRCs}$ in vitro and in vivo, FoxO3A was highly expressed into the nuclei of tumor cells in SB202190-treated $\mathrm{Apc}^{\mathrm{Min}}$ mice (Figure 7e) and its nuclear accumulation correlated with increased expression of its target genes p21 and PTEN (Figure 7e). These results provide evidence that the cytotoxic and cytostatic effects produced by SB202190 treatment in vivo are mediated by the induction of FoxO-dependent transcription.

\section{Discussion}

The efficacy of current cancer therapies rely essentially on its DNA damaging ability, which is expected to promote 

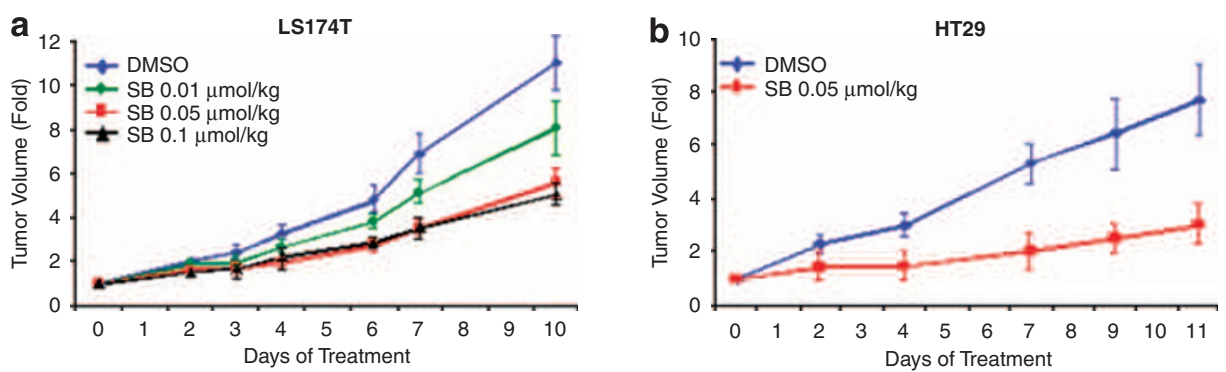

c

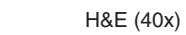

$H \& E(200 x)$

$\operatorname{Ki67}(200 x)$
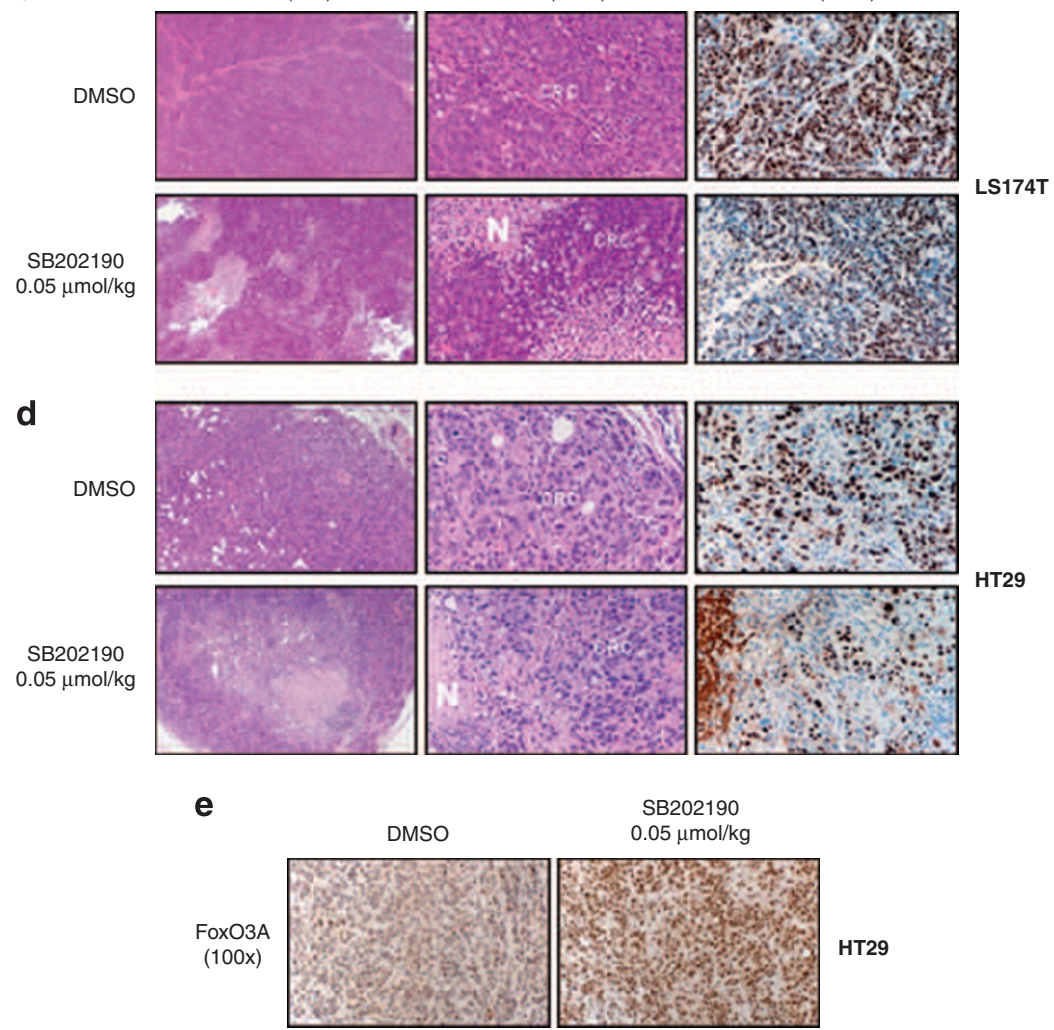

Figure 6 SB202190 inhibits colorectal cancer growth in vivo. (a and b) Tumor growth kinetics of CRCs. A total of $5 \times 10^{6}$ LS174T or $10 \times 10^{6} \mathrm{HT} 29$ cells were injected subcutaneously into each flank of nude C57BL/6 mice. Mice were treated daily by i.p. injection of the indicated doses of SB202190 or vehicle alone, starting when tumors reached a mean volume of $60 \mathrm{~mm}^{3}$. Animals were killed when control tumors reached a mean volume of $650 \mathrm{~mm}^{3}$. Ten tumors per condition were analyzed, except for the LS174T experiment (a), in which the control group $(n=24)$ was enlarged to test three different DMSO concentrations corresponding to the diverse doses of SB202190 treatment. Mice of this group behave similarly with regard to all the parameters we analyzed. (c and d) Hematoxylin and eosin (H\&E) staining showing a significant tumor regression, characterized by areas of inflammation and necrosis $(\mathrm{N}$ ) in SB202190-treated tumors compared with controls (left panel, $40 \times$; medium panel, $200 \times$ ). Ki67 staining indicating a significant reduction of the proliferation index in SB202190-treated tumors compared with controls (right panel, $200 \times$ ). (e) Immunohistochemical staining showing nuclear accumulation of FoxO3A in SB202190-treated tumors versus controls (DMSO)

apoptosis. However, DNA mutations involving apoptotic and/or anti-apoptotic genes cause the acquisition of drug resistance in CRCs. ${ }^{12}$ Hence, other types of cell death might prove more effective therapeutic targets for colorectal tumors. Recent observations indicate that some types of cancer cells display features of non-apoptotic cell death, defined as autophagic cell death, in response to chemotherapy or radiation. These findings suggest that pharmacological manipulation of autophagy might represent a promising tool in cancer treatment. Still, the role of autophagy in cancer biology and therapy is quite controversial, as other observations indicate that solid tumors, defective in apoptosis, rely on autophagy to survive under metabolic stress conditions. ${ }^{35}$

This study shows that on p38 $\alpha$ inhibition CRCs activate autophagy to survive metabolic stress, but persistent stress conditions trigger cell death. Indeed, p38 $\alpha$ blockade causes a significant decrease in the intracellular levels of ATP, which correlates with the impaired expression of rate-limiting enzymes involved in aerobic glycolysis, the most important source of energy for these cells. This failure is associated with a time-dependent reduction of HIF1 $\alpha$ protein levels and the consequent significant decrease in $\mathrm{HIF} 1 \alpha$ target gene 
a

OM-treated $\mathrm{Apc}^{\text {Min }}$ mice

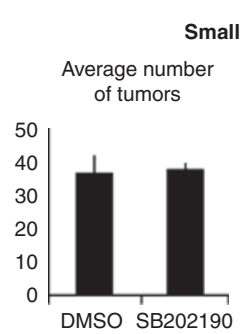

Small Intestin

b
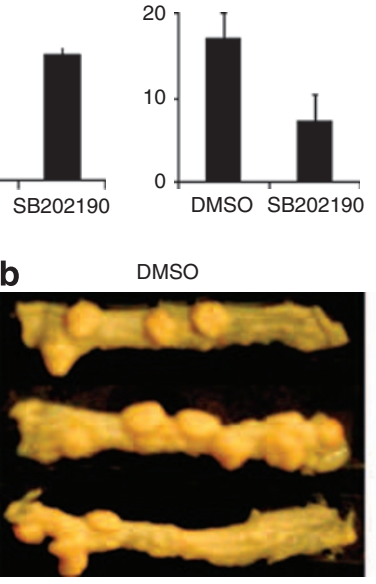

so

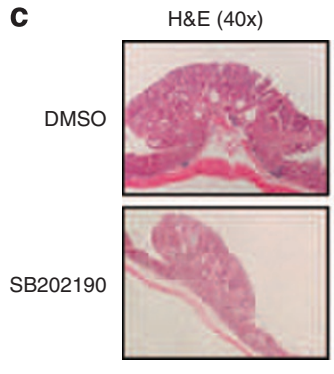

e

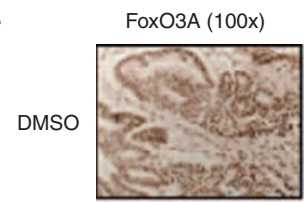

H\&E (100x)

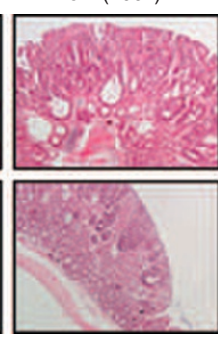

p21 (100x)

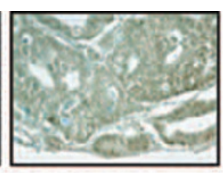

SB202190
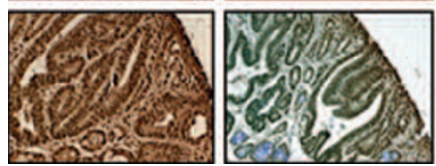

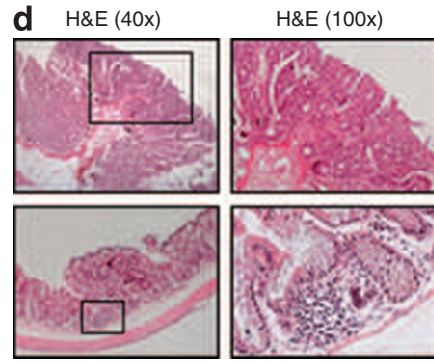

PTEN (100x)

PCNA (100x)

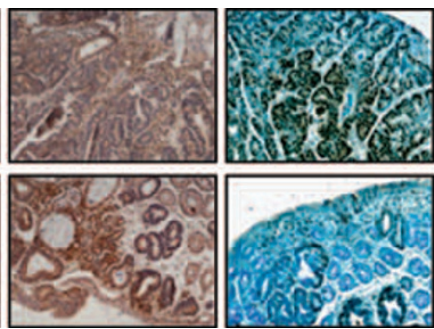

Figure 7 SB202190 inhibits colorectal cancer growth in AOM-treated Apc ${ }^{\mathrm{Min}}$ mice. AOM-treated Apc ${ }^{\mathrm{Min}}$ mice were subjected to daily i.p injections of SB202190 0.05 $\mu$ mol/kg body weight $(n=10)$ or vehicle alone $(n=10)$ for 2 weeks before being sacrificed. ( $(\mathbf{a}$ and $\mathbf{b}$ ) Tumors from small intestine and colon specimens of treated and control animals were stained with methylene blue, counted and measured. (c and d) Hematoxylin and eosin (H\&E) staining illustrating the histological features of tumors from AOM-treated Apc ${ }^{\text {Min }}$ mice after 2 weeks of daily administration of SB202190 compared with controls. Boxes indicate location of magnified areas of malignant progression (d, upper panel - DMSO) or foci of inflammatory cell replacing adenomatous glands (d, lower panel - SB202190). (e) Immunohistochemical stainings showing protein expression levels of FoxO3A, p21, PTEN and PCNA in SB202190-treated tumors versus controls (DMSO)

expression. Among HIF1 $\alpha$ target genes, GLUT1, HK2, PKM2 and $L D H A$ are rapidly downregulated and maintained at decreased expression levels for longer time points. It is worth noting that knockdown of $L D H A$ has been proven to severely diminish tumorigenicity of cancer cells in mice. ${ }^{36}$ The resulting acute energy need is first buffered by the induction of autophagy, which is sustained by a robust transcriptional response of the ATG genes largely dependent on the transcription factor FoxO3A. The induction of FoxO target genes involved in metabolism - PGC1a, PEPCK, UCP2 - suggests that, in response to $\mathrm{p} 38 \alpha$ inhibition, CRCs activate a transcriptional program leading to the expression of enzymes responsible for the conversion of amino acids and fatty acids - the end products of the autophagic cascade - as energy fuel to survive. Indeed, SB202190-treated CRCs also express CPT-1 and MCAD, two enzymes involved in fatty acid catabolism (data not shown).

After p38 $\alpha$ inhibition, autophagy is accompanied by $\mathrm{G} 1$ arrest (Chiacchiera, Martelli and Simone, unpublished results), probably as an attempt to retain energy to survive. FoxO3A upregulates the transcriptional repressor Bcl-6, which inhibits cyclin $D$ expression, ${ }^{25}$ together with the cdk 
inhibitors p21 and p27, and RBL2/p130, finally leading to the transcriptional repression and/or inhibition of downstream proteins involved in the G1/S transition.

Prolonged inactivation of $\mathrm{p} 38 \alpha$ by SB202190 treatment leads to cell death and is accompanied by the increased expression of FoxO target genes encoding for the BH3-only proteins BNIP3L, BNIP3, PUMA and Bim. BNIP3 and BNIP3L proteins localize to the mitochondria and have been shown to play a role in non-apoptotic cell death. ${ }^{37}$ Transmission electron microscopy analysis revealed a consistent similarity between SB202190-treated HT29 cells and 293T cells overexpressing BNIP3, with both cell lines displaying heterochromatic nuclei and autophagic features into the cytoplasm. ${ }^{19,37}$ However, autophagic cell death is a controversial phenomenon, simply defined by the presence of autophagic markers in dying cells. ${ }^{35}$ Indeed, the effectors and mediators involved in this process are not well established yet. Our earlier morphological and qualitative analysis of SB202190-treated cells showed that dying cells did not present apoptotic features such as nuclear segmentation or DNA fragmentation. ${ }^{19}$ In this study, evaluation of SB202190-treated tumor xenografts revealed the presence of expanded areas of necrosis, with no considerable differences in the accumulation of apoptotic nuclear debris between treated and untreated tumors. However, further studies are awaited to precisely characterize the type of cell death induced by p38 $\alpha$ blockade in CRCs.

To our knowledge, a direct connection between p38 $\alpha$ and FoxO3A has not been reported. Actually, other signaling pathways, such as $\mathrm{PI}_{3} \mathrm{~K} /$ Akt and JNK, influence FoxO cellular localization and activity by phosphorylation, and have been reported to cross talk with $\mathrm{p} 38 \alpha$ in a cell type-specific and signal-dependent manner. Indeed, the $\mathrm{PI}_{3} \mathrm{~K} / \mathrm{Akt}$ cascade cooperates with $\mathrm{p} 38 \alpha / \beta$ at the chromatin level to regulate muscle-specific gene expression; ${ }^{10,15}$ moreover, in human breast cancer cells p38 $\alpha / \beta$ activate Akt through MAPKAPK2dependent phosphorylation of serine $473 .{ }^{38}$ Conversely, JNK signaling is antagonized in many different ways by $\mathrm{p} 38 \alpha$, including direct repression of the JNK upstream kinases Grap2/HPK1 and MKK7, in fetal hematopoietic, MEFs, muscle and liver/tumor cells. ${ }^{13,16}$

In this study, we show that AMPK is required for SB202190dependent nuclear localization of FoxO3A. Although the underlying molecular mechanism remains unclear, pharmacological blockade of AMPK or its genetic ablation by specific RNAi indicate that the activity of this kinase is necessary for the nuclear accumulation of $\mathrm{FoxO} 3 \mathrm{~A}$ and the subsequent activation of FoxO3A target genes involved in autophagy, metabolism, cell cycle arrest and cell death. It is interesting to note that a recent study describes the direct phosphorylation of FoxO3A by AMPK, with mutations in the phospho-acceptor sites impairing the transcriptional activation, but not the cellular localization, of exogenous FoxO3A in 293 cells. $^{29}$ In our experimental model, the nuclear pool of endogenous FoxO3A is both enriched and hyperphosphorylated at serine and threonine residues in response to $338 \alpha$ inhibition in CRCs (Chiacchiera and Simone, unpublished results). However, because of the concomitant modulation of other important signaling pathways, such as p38 $\alpha$ itself, Akt and JNK, at this stage a direct mechanism involving the phosphorylation of FoxO3A by AMPK can only be hypothesized.
The three above-mentioned pathways are all known to play a significant role in the regulation of autophagy. The $\mathrm{PI}_{3} \mathrm{~K}$ class I enzymes are part of a signaling cascade that negatively regulates autophagy in several cellular systems including CRCs, as confirmed by the positive role in the autophagic process exerted by $\mathrm{PTEN}$, the $\mathrm{PI}_{3} \mathrm{~K}$ class I specific phosphatase, in HT29 cells. $^{39}$ It is interesting to note that FoxO3A binds to the promoter of and induces PTEN transcription, suggesting the presence of a negative feedback loop that possibly accounts for the time-dependent reduction of Akt phospho-activation and kinase activity observed in SB202190-treated CRCs. The JNK pathway has also been reported to be required for starvation-induced autophagy in cancer cells and for autophagic cell death. ${ }^{40,41}$ The AMPK pathway, which becomes activated when AMP levels overcome those of ATP, is required for autophagy induction in HT29 CRCs. ${ }^{42}$ Activated AMPK inhibits ACC, which regulates the formation of fatty acids, and induces CPT-1 activity and $\beta$-oxidation with a consequent increase in the ATP/AMP ratio. These findings are in accordance with the gene expression reprograming observed after $\mathrm{p} 38 \alpha$ blockade in CRCs.

Our data confirm the relevance of the energetic metabolism for $\mathrm{CRC}$ fate. As a consequence of functional deregulation of critical pathways, endogenous control mechanisms are bypassed and the cells acquire the ability to survive the environmental stress associated with increased growth in unfavorable conditions of nutrients and oxygen shortage. One of the most common adaptation of cancer cells is the constitutive activation of aerobic glycolysis through deregulation of one or more of the sequential steps involved in the glycolytic pathway, although how this metabolic modification actually represents a growth advantage has not yet been understood. This phenomenon, called the 'Warburg effect', is already successfully exploited for diagnosis by positron emission tomography, using the glucose analog tracer 18-flourodeoxyglucose, ${ }^{43}$ and renders the cancer-specific metabolism a highly attractive target for cancer therapy.

In this study, we provide evidences in support of the possible development of a therapeutic strategy for colorectal cancer, on the basis of the pharmacological blockade of the p38 $\alpha$ pathway, in association with drugs targeted to cancerspecific metabolic pathways and/or autophagy. Indeed, our results show that inhibition of p38 $\alpha$ triggers FoxO-dependent transcriptional activation, leading to a striking anti-tumor effect both in cultured cell lines and in in vivo cancer models, such as xenografted nude mice and $\mathrm{AOM}$-treated $\mathrm{Apc}^{\mathrm{Min}}$ mice, this latter being the most widely used animal model for genetic and sporadic colorectal cancer. The potential use of molecules targeted against $p 38 \alpha$ is further supported by the fact that several $p 38 \alpha$ inhibitors are already in clinical trials for inflammatory diseases. ${ }^{44}$

\section{Materials and Methods}

Cell culture, reagents and ATP assay. HT-29 and LS174T cells were maintained in DMEM and RPMI 1640, respectively, supplemented with 10\% FBS, avoiding confluence at any time. SB202190 $(5-10 \mu \mathrm{M})$ was purchased from Calbiochem; propidium iodide, trypan blue, Compound $C(5-10 \mu \mathrm{M})$ were purchased from Sigma. ATP levels were determined by luciferine-luciferase assay; equal number of SB202190-treated and DMSO control cells were processed 
using the ATP Bioluminescence Assay kit (Roche) according to standard protocol. Measurements were done in quintuplicate.

In vivo studies. $10 \times 10^{6} \mathrm{HT} 29$ or $5 \times 10^{6}$ LS174T cells were injected subcutaneously into the flanks $(0.2 \mathrm{ml}$ per flank) of male athymic nude C57BL/6 mice. The volume of the tumors was measured every $2-3$ days. Mice were treated daily by i.p. injection of SB202190 or vehicle alone in sterile saline. The treatment started when tumors reached a mean volume of $60 \mathrm{~mm}^{3}$. Animals were killed when control tumors reached a mean volume of $650 \mathrm{~mm}^{3}$.

$\mathrm{Apc}^{\mathrm{Min}}$ mice (4-month-old) were first administered with AOM (Sigma) $14 \mathrm{mg} / \mathrm{kg}$ body weight once a week for 4 weeks, then, 1 month later, they were subjected to daily i.p. injections of SB202190 $0.05 \mu \mathrm{mol} / \mathrm{kg}$ body weight for 14 days before being killed.

Procedures involving animals and their care were conducted in conformity with the institutional guidelines that are in compliance with national and international laws and policies.

Quantitative real-time PCR. Total RNA was extracted with TRIzol reagent (Invitrogen) following manufacturer's instructions. Samples were then treated with DNAase-1 (Ambion). Total RNA (1-4 $\mu \mathrm{g}$ ) was retro-transcribed using High Capacity DNA Archive Kit (Applied Biosystem) following manufacturer's instructions. PCRs were carried out in triplicate using the $\mathrm{ABI} 7500 \mathrm{HT}$ machine (Applied Biosystem). For all experiments the following PCR conditions were used: $95^{\circ} \mathrm{C}$ for $10 \mathrm{~min}$, followed by 40 cycles at $95^{\circ} \mathrm{C}$ for $15 \mathrm{~s}$ and $60^{\circ} \mathrm{C}$ for $60 \mathrm{~s}$. The quantitative normalization of the cDNA in each sample was carried out using GAPDH and $\beta$-actin amplification as internal control. Relative quantification was done using the $\Delta \Delta \mathrm{C}_{\mathrm{T}}$ method

Primers sequences are available on request.

Chromatin immunoprecipitation (ChIP) analysis. Chromatin immunoprecipitation analysis was conducted as described earlier. ${ }^{15}$ The following antibodies were used: rabbit anti-FoxO3A (Santa Cruz Biotechnology), antiphospho serine 5 RNApolll (H14, Covance) and rabbit anti-LDH (Santa Cruz Biotechnology). Real-time PCRs were carried out using the SybrGreen Master Mix at least thrice using three independent samples. Data reported in figures are values normalized to input DNA and to values from a non-related antibody (anti-LDH), which were set as the background (one unit) in each calculation.

Primers sequences are available on request.

RNA interference. HT-29 cells were seeded in a 30-mm dish and transfected with $100 \mathrm{nM}$ siRNA using RNAiMAX (Invitrogen) following manufacturer's instructions. One siRNA was used for FoxO3A (sequence $5^{\prime}$-GACAAUAGC AACAAGUAUA- $3^{\prime}$ ) and AMPK (sequence $5^{\prime}$-GAGGAGCUAUUUGAUUA- $3^{\prime}$ ), whereas two different siRNAs were used for p38 $\alpha$ (sequences $5^{\prime}$-GUGAAAU GUCAGAAGCUUA-3' and $5^{\prime}$-CCAAAUUCUCCGAGGUCUA-3'). On-TARGET-plus control siRNAs (Thermo Scientific) were used as control sequences.

\section{Nuclear/cytoplasmic fractionation and immunoblot} analysis. Nucleocytoplasmic fractionation was carried out using the ProteoExtract subcellular proteome extraction kit (Calbiochem). Immunoblots were carried out according to Cell Signaling's instructions. Briefly, cells were homogenized in $1 \times$ lysis buffer $(50 \mathrm{mM}$ Tris-HCl pH7.4; $5 \mathrm{mM}$ EDTA; $250 \mathrm{mM}$ $\mathrm{NaCl}$ and $0.1 \%$ Triton $\mathrm{X}-100$ ) supplemented with protease and phosphatase inhibitors ( $1 \mathrm{mM}$ PMSF; $1.5 \mu \mathrm{M}$ pepstatin A; $2 \mu \mathrm{M}$ leupeptin; $10 \mu \mathrm{g} / \mathrm{ml}$ aprotinin, $5 \mathrm{mM} \mathrm{NaF}$ and $1 \mathrm{mM} \mathrm{Na}_{3} \mathrm{VO}_{4}$ ). A total of $15-20 \mu \mathrm{g}$ of protein extracts from each sample were denatured in $5 \times$ Laemmli sample buffer and used for western blots analysis. Western blots were executed using anti-actin (Sigma), anti-posphoAKT (Ser473), anti-Akt, anti-phosphoAMPK (Thr172), anti-AMPK, anti-p38 $\alpha$, antiphosphoMAPKAPK2 (Thr334), anti-phosphoATF2 (Thr71), anti-HK2 (all from Cell Signaling), anti-Fox03A, anti-phosphoFoxo3A (Thr32), anti-phosphoFox03A (Ser253), anti-JNK, anti-phosphoJNK, anti-p300, anti-BNIP3L, anti- $\beta$ tubulin, anticyclinE, anti-p21, anti-PTEN (all from Santa Cruz Biotechnology), anti-RBL2/p130 (BD transduction), anti-HIF1 $\alpha$ (Abcam) and anti-Gaparapl1 (Proteintech Group Inc.). Western blot was developed with the ECL-plus chemiluminescence reagent (GE Healthcare) as per manufacturer's instructions. The densitometric evaluation was carried out by ImageJ software.

Immunofluorescent stainings. Cells were seeded on glass coverslips and after $12 \mathrm{~h}$ were treated as indicated. At the end of the treatment cells were fixed in $4 \%$ paraformaldehyde and permeabilized using $0.01-0.1 \%$ Triton X-100. Coverslips were incubated with the indicated primary antibodies. Secondary antibodies were Alexa Fluor 488 and Alexa Fluor 594 from Invitrogen; nuclei were counterstained using propidium iodide (Sigma). Slides were sealed using Vectashield mounting medium (Vector Laboratories). Images were acquired using a Zeiss LSM-5 Pascal confocal microscopy.

Histology and immunohistochemistry. LS174T- and HT29-derived or AOM-treated Apc ${ }^{\mathrm{Min}}$ mice colorectal tumor specimens were fixed overnight in $10 \%$ neutral-buffered formalin, embedded in paraffin, sectioned at 4- $\mu \mathrm{m}$ thickness and stained with hematoxylin and eosin. Additional sections, collected on poly-L-lysinecoated slides, were used for immunohistochemical stains, which were carried out with avidin/biotin-based detection systems. Sections were incubated with antibodies against Ki-67 (Dako), FoxO3A (Abcam), PTEN (Cell Signaling), p21 and PCNA (Santa Cruz), with overnight incubations at $4^{\circ} \mathrm{C}$.

A summary diagram reporting our findings is shown below.

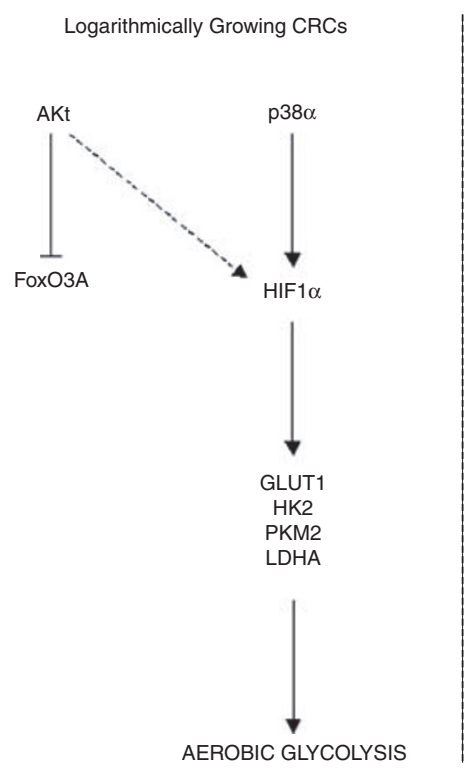

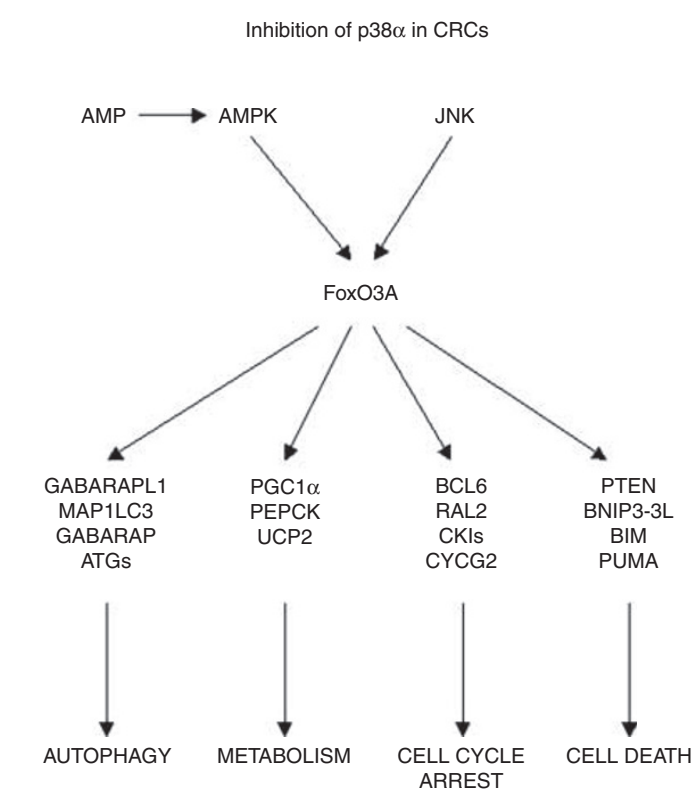


Acknowledgements. We thank Dr. Francesco Paolo Jori for his helpful discussion during the preparation of the manuscript and editorial assistance and Dr. Nicola Martelli for technical assistance. Dr. Chiacchiera and Dr. Matrone are supported by FIRC (Italian Foundation for Cancer Research) and AIRC (Italian Association for Cancer Research) fellowships, respectively.

This work was partially supported by a 'My First Grant' (to CS) and a 'Start-Up Grant' (to AM) from the Italian Association for Cancer Research and by a grant from 'Fondazione Negri Sud ONLUS' (to CS). CS is grateful to his wife Viviana for continuous encouragement and support.

1. Jemal A, Murray T, Ward E, Samuels A, Tiwari RC, Ghafoor A et al. Cancer statistics. CA Cancer J Clin 2005; 55: 10-30.

2. Wood LD, Parsons DW, Jones S, Lin J, Sjöblom T, Leary RJ et al. The genomic landscapes of human breast and colorectal cancers. Science 2007; 318: 1108-1113.

3. Rustgi AK. The genetics of hereditary colon cancer. Genes Dev 2007; 21: 2525-2538.

4. Kinzler KW, Vogelstein B. Lessons from hereditary colorectal cancer. Cell 1996; 87: 159-170.

5. Denko NC. Hypoxia, HIF1 and glucose metabolism in the solid tumour. Nat Rev Cancer 2008; 8: 705-713.

6. Gatenby RA, Gillies RJ. Why do cancers have high aerobic glycolysis? Nat Rev Cancer 2004; 4: 891-899.

7. Kroemer G, Pouyssegur J. Tumor cell metabolism: cancer's Achilles' heel. Cancer Cell 2008; 13: 472-482.

8. Minet E, Michel G, Mottet D, Raes M, Michiels C. Transduction pathways involved in hypoxiainducible factor-1 phosphorylation and activation. Free Radic Biol Med 2001; 31: 847-855.

9. Hui L, Bakiri L, Mairhorfer A, Schweifer N, Haslinger C, Kenner L et al. p38alpha suppresses normal and cancer cell proliferation by antagonizing the JNK-c-Jun pathway. Nat Genet 2007; 39: 741-749.

10. Simone C, Forcales SV, Hill DA, Imbalzano AN, Latella L, Puri PL. p38 pathway targets SWI-SNF chromatin-remodeling complex to muscle-specific loci. Nat Genet 2004; 36: 738-743.

11. Puigserver $P$, Rhee J, Lin J, Wu Z, Yoon JC, Zhang CY et al. Cytokine stimulation of energy expenditure through p38 MAP kinase activation of PPARgamma coactivator-1. Mol Cell 2001; 8: 971-982.

12. Chiacchiera F, Simone C. Signal-dependent regulation of gene expression as a target for cancer treatment: inhibiting p38alpha in colorectal tumors. Cancer Lett 2008; 265: $16-26$.

13. Perdiguero E, Ruiz-Bonilla V, Serrano AL, Muñoz-Cánoves $P$. Genetic deficiency of p38alpha reveals its critical role in myoblast cell cycle exit: the p38alpha-JNK connection. Cell Cycle 2007; 6: 1298-1303.

14. Jacquet S, Zarrinpashneh E, Chavey A, Ginion A, Leclerc I, Viollet B et al. The relationship between p38 mitogen-activated protein kinase and AMP-activated protein kinase during myocardial ischemia. Cardiovasc Res 2007; 76: 465-472.

15. Serra C, Palacios D, Mozzetta C, Forcales SV, Morantte I, Ripani M et al. Functional interdependence at the chromatin level between the MKK6/p38 and IGF1/PI3K/AKT pathways during muscle differentiation. Mol Cell 2007; 28: 200-213.

16. Ventura JJ, Tenbaum S, Perdiguero E, Huth M, Guerra C, Barbacid M et al. p38alpha MAP kinase is essential in lung stem and progenitor cell proliferation and differentiation. Nat Genet 2007; 39: 750-758.

17. Kuwamura H, Tominaga K, Shiota M, Ashida R, Nakao T, Sasaki E et al. Growth inhibition of colon cancer cells by transfection of dominant-negative apoptosis signal-regulating kinase-1. Oncol Rep 2007; 17: 781-786.

18. Gout S, Morin C, Haule F, Huot J. Death receptor-3, a new E-Selectin counter-receptor that confers migration and survival advantages to colon carcinoma cells by triggering p38 and ERK MAPK activation. Cancer Res 2006; 66: 9117-9124.

19. Comes F, Matrone A, Lastella P, Nico B, Susca FC, Bagnulo R et al. A novel cell typespecific role of p38alpha in the control of autophagy and cell death in colorectal cancer cells. Cell Death Differ 2007; 14: 693-702.

20. Klionsky DJ, Abeliovich H, Agostinis P, Agrawal DK, Aliev G, Askew DS et al. Guidelines for the use and interpretation of assays for monitoring autophagy in higher eukaryotes. Autophagy 2008; 4: 151-175.
21. Simone C. Signal-dependent control of autophagy and cell death in colorectal cancer cell: the role of the p38 pathway. Autophagy 2007; 3: 468-471.

22. Wang S, Mintz A, Mochizuki K, Dorsey JF, Ackermann JM, Alavi A et al. Multimodality optical imaging and $18 \mathrm{~F}$-FDG uptake in wild-type p53-containing and p53-null human colon tumor xenografts. Cancer Biol Ther 2007; 6: 1649-1653.

23. Karanam S, Moreno CS. CONFAC: automated application of comparative genomic promoter analysis to DNA microarray datasets. Nucleic Acids Res 2004; 32 (Web Server issue): W475-W484.

24. Calnan DR, Brunet A. The FoxO code. Oncogene 2008; 27: 2276-2288.

25. Ho KK, Myatt SS, Lam EW. Many forks in the path: cycling with FoxO. Oncogene 2008; 27 : 2300-2311.

26. van der Horst A, Burgering BM. Stressing the role of FoxO proteins in lifespan and disease. Nat Rev Mol Cell Biol 2007; 8: 440-450.

27. Mammucari C, Milan G, Romanello V, Masiero E, Rudolf R, Del Piccolo P et al. FoxO3 controls autophagy in skeletal muscle in vivo. Cell Metab 2007; 6: 458-471.

28. Zhao J, Brault JJ, Schild A, Cao P, Sandri M, Schiaffino S et al. FoxO3 coordinately activates protein degradation by the autophagic/lysosomal and proteasomal pathways in atrophying muscle cells. Cell Metab 2007; 6: 472-483.

29. Greer EL, Oskoui PR, Banko MR, Maniar JM, Gygi MP, Gygi SP et al. The energy sensor AMP-activated protein kinase directly regulates the mammalian $\mathrm{FOXO} 3$ transcription factor. J Biol Chem 2007; 282: 30107-30119.

30. Emerling BM, Platanias LC, Black E, Nebreda AR, Davis RJ, Chandel NS. Mitochondrial reactive oxygen species activation of p38 mitogen-activated protein kinase is required for hypoxia signaling. Mol Cell Biol 2005; 25: 4853-4862.

31. Kwon SJ, Song JJ, Lee YJ. Signal pathway of hypoxia-inducible factor-1alpha phosphorylation and its interaction with von Hippel-Lindau tumor suppressor protein during ischemia in MiaPaCa-2 pancreatic cancer cells. Clin Cancer Res 2005; 11: 7607-7613.

32. Paulsen JE, Steffensen IL, Løberg EM, Husøy T, Namork E, Alexander J. Qualitative and quantitative relationship between dysplastic aberrant crypt foci and tumorigenesis in the Min/+ mouse colon. Cancer Res 2001; 61: 5010-5015.

33. Suzui M, Okuno M, Tanaka T, Nakagama H, Moriwaki H. Enhanced colon carcinogenesis induced by azoxymethane in min mice occurs via a mechanism independent of betacatenin mutation. Cancer Lett 2002; 183: 31-41.

34. Issa AY, Volate SR, Muga SJ, Nitcheva D, Smith T, Wargovich MJ. Green tea selectively targets initial stages of intestinal carcinogenesis in the AOM-ApcMin mouse model. Carcinogenesis 2007; 28: 1978-1984.

35. White E. Autophagic cell death unraveled: Pharmacological inhibition of apoptosis and autophagy enables necrosis. Autophagy 2008; 4: 399-401.

36. Fantin VR, St-Pierre J, Leder P. Attenuation of LDH-A expression uncovers a link between glycolysis, mitochondrial physiology, and tumor maintenance. Cancer Cell 2006; 9: 425-434.

37. Vande Velde C, Cizeau J, Dubik D, Alimonti J, Brown T, Israels S et al. BNIP3 and genetic control of necrosis-like cell death through the mitochondrial permeability transition pore. Mol Cell Biol 2000; 20: 5454-5468.

38. Rane MJ, Coxon PY, Powell DW, Webster R, Klein JB, Pierce W et al. p38 Kinasedependent MAPKAPK-2 activation functions as 3-phosphoinositide-dependent kinase-2 for Akt in human neutrophils. J Biol Chem 2001; 276: 3517-3523.

39. Arico S, Petiot A, Bauvy C, Dubbelhuis PF, Meijer AJ, Codogno P et al. The tumor suppressor PTEN positively regulates macroautophagy by inhibiting the phosphatidylinositol 3-kinase/protein kinase B pathway. J Biol Chem 2001; 276 35243-35246.

40. Wei Y, Pattingre S, Sinha S, Bassik M, Levine B. JNK1-mediated phosphorylation of Bcl-2 regulates starvation-induced autophagy. Mol Cell 2008; 30: 678-688.

41. Yu L, Alva A, Su H, Dutt P, Freundt E, Welsh S et al. Regulation of an ATG7-beclin 1 program of autophagic cell death by caspase-8. Science 2004; 304: 1500-1502.

42. Meley D, Bauvy C, Houben-Weerts JH, Dubbelhuis PF, Helmond MT, Codogno P et al. AMP-activated protein kinase and the regulation of autophagic proteolysis. J Biol Chem 2006; 281: 34870-34879.

43. Gambhir SS. Molecular imaging of cancer with positron emission tomography. Nat Rev Cancer 2002; 2: 683-693.

44. Lee MR, Dominguez C. MAP kinase p38 Inhibitors: clinical results and an intimate look at their interactions with p38 protein. Curr Med Chem 2005; 12: 2979-2994.

\section{Supplementary Information accompanies the paper on Cell Death and Differentiation website (http://www.nature.com/cdd)}

